\title{
PENGARUH STRES KERJA TERHADAP TURNOVER INTENTION YANG DIMEDIASI OLEH KEPUASAN KERJA
}

\author{
Putu Sofia Andi Dewi ${ }^{1}$ \\ Anak Agung Ayu Sriathi ${ }^{2}$ \\ ${ }^{1,2}$ Fakultas Ekonomi dan Bisnis Universitas Udayana (Unud), Bali, Indonesia \\ E-mail: sofiaandidewi@gmail.com
}

\begin{abstract}
ABSTRAK
Penelitian ini bertujuan untuk mengetahui pengaruh stres kerja dan kepuasan kerja terhadap turnover intention dan juga mengetahui peran kepuasan kerja dalam memediasi pengaruh antara stres kerja dan turnover intention. Hasil analisis menunjukan bahwa stres kerja berpengaruh positif dan signifikan terhadap turnover intention. Stres kerja berpengaruh negatif dan signifikan terhadap kepuasan kerja. Kepuasan kerja berpengaruh negatif dan signifikan terhadap turnover intention. Hasil penelitian ini juga menunjukkan bahwa kepuasan kerja memediasi stres kerja terhadap turnover intention. Jumlah sampel yang diambil sebanyak 72 orang karyawan, dengan metode proportionate stratified random sampling. Teknik analisis yang digunakan dalam penelitian ini adalah path analysis dan uji sobel. Untuk menurunkan turnover intention, pihak rumah sakit harus dapat mengendalikan tingkat stres karyawan dengan cara memperhatikan antara beban kerja yang diberikan dengan kapasitas kerja individu dan juga waktu diberikan dalam menyelesaikan pekerjaan. Pihak rumah sakit juga disarankan memberikan penghargaan kepada karyawan yang sudah mengerjakan tugasnya dengan baik.
\end{abstract}

Kata kunci : stres kerja, kepuasan kerja, turnover intention

\begin{abstract}
This study aims to determine the effect of work stress and job satisfaction on turnover intention and also to know the role of job satisfaction in mediating the influence between work stress and turnover intention. The number of samples taken was 72 employees, using the proportionate stratified random sampling method. The analysis technique used in this study is path analysis and sobel test. The results of the analysis show that work stress has a positive and significant effect on turnover intention. Job stress has a negative and significant effect on job satisfaction. Job satisfaction has a negative and significant effect on turnover intention. The results of this study also show that job satisfaction mediates work stress on turnover intention. To reduce turnover intention, the hospital must be able to control the stress level of employees by paying attention to the workload given to individual work capacity and also the time given in completing work. The hospital is also advised to give awards to employees who have done their jobs well.

Keywords: job stress, job satisfaction, turnover intention
\end{abstract}




\section{PENDAHULUAN}

Sumber daya manusia merupakan hal yang penting dalam menentukan keefektifan suatu organisasi. Oleh karena itu sebuah organisasi perlu melakukan investasi dengan melaksanakan fungsi Manajemen Sumber Daya Manusia (MSDM) yaitu mulai perekrutan, penyeleksian sampai mempertahankan sumber daya manusianya. Akan tetapi fenomena yang sering terjadi adalah di saat kinerja suatu perusahaan yang telah demikian bagus dapat terganggu, baik secara langsung maupun tidak langsung oleh berbagai perilaku karayawan yang sulit dicegah terjadinya. Salah satu bentuk perilaku karyawan tersebut adalah keinginan berpindah (turnover intention) yang dapat berujung pada keputusan karyawan untuk meninggalkan pekerjaannya. Turnover intention merupakan suatu keadaan dimana pekerja memiliki niat atau kecenderungan yang dilakukan secara sadar untuk mencari suatu pekerjaan lain sebagai alternatif di organisasi yang berbeda dan turnover adalah penggerak keluarnya tenaga kerja dari tempatnya bekerja (Abdillah, 2012). Turnover yang tinggi dapat berdampak buruk bagi organisasi seperti menciptakan ketidakstabilan dan ketidakpastian terhadap kondisi tenaga kerja yang ada serta tingginya biaya pengelolaan SDM seperti biaya pelatihan yang sudah dilakukan pada karyawan sampai dengan biaya rekrutmen dan pelatihan kembali(Sartika, 2014).

Sebagai salah satu bentuk organisasi, rumah sakit merupakan organisasi yang bergerak di bidang pelayanan kesehatan. Ada 2 jenis rumah sakit di Indonesia, yaitu rumah sakit pemerintah dan rumah sakit non-pemerintah atau yang biasa disebut rumah sakit swasta. Rumah sakit yang ada sampai saat ini 
sudah semakin banyak sehingga menimbulkan persaingan yang cukup ketat antar rumah sakit. Rumah sakit pada saat ini harus bersaing dengan praktek dokter, praktek bidan dan pelayanan kesehatan lainnya, bukan hanya bersaing antar rumah sakit lainnya. Rumah Sakit Bali Royal Hospital merupakan salah satu rumah sakit yang beroperasi di Bali. Rumah sakit ini dibangun pada bulan Maret 2009 dan baru beroperasi pada bulan Juli 2010. Rumah Sakit BROS berlokasi di Jalan Tantular No.6 Renon Denpasar, yang memiliki berbagai fasilitas kesehatan baik itu rawat jalan, rawat inap, dan medical check up. Dukungan tenaga SDM yang berkualitas dan profesional, memastikan BROS dapat memberikan layanan kesehatan yang baik bagi masyarakat.

Sebagai salah satu rumah sakit yang berdiri di Bali, Rumah Sakit Bali Royal Hospital (BROS) harus mampu lebih selektif dalam melakukan perekrutan karyawannya. Setelah mengalami beberapa kali pergantian karyawan, tercatat sampai Desember 2017 sebanyak 27 orang meninggalkan perusahaan dalam kurun waktu satu tahun. Hal ini tentunya membuat manajemen Rumah Sakit BROS harus kembali melakukan rekrutmen, seleksi dan pelatihan bagi caloncalon karyawan yang akan mengisi kekosongan posisi yang ditinggalkan oleh karyawan sebelumnya. Selain itu, pihak manajemen juga harus berupaya agar karyawan yang masih bertahan di Rumah Sakit BROS bisa berkomitmen penuh terhadap perusahaan, sehingga tidak muncul keinginan untuk mengundurkan diri dan keluar dari perusahaan yang dapat menimbulkan tingginya biaya pengelolaan Sumber Daya Manusia (SDM). 
Rumah Sakit Bali Royal Hospital sangat sesuai untuk dilakukan penelitian mengenai turnover intention. Hal ini didukung dengan data pencatatan mengenai karyawan masuk dan keluar yang ditunjukkan pada tingkat turnover yang terjadi pada perusahaan pada tahun 2017. Data ini dapat mendukung penelitian turnover intention yang ditunjukkan pada permasalahan turnover karyawan Rumah Sakit Bali Royal Hospital pada Tabel 1.

Tabel 1.

Tingkat Turnover Rumah Sakit Bali Royal Hospital Tahun 2017

\begin{tabular}{cccccc}
\hline Tahun & Bulan & $\begin{array}{c}\text { Jumlah } \\
\text { Karyawan } \\
\text { Awal } \\
\text { (Orang) }\end{array}$ & $\begin{array}{c}\text { Jumlah } \\
\text { Karyawan } \\
\text { Akhir } \\
\text { (Orang) }\end{array}$ & $\begin{array}{c}\text { Jumlah } \\
\text { Karyawan } \\
\text { Keluar } \\
\text { (Orang) }\end{array}$ & Turnover (persen) \\
\hline \multirow{6}{*}{ (Orang } & $(2)$ & $(3)$ & $(4)=\frac{(3)}{(1)+(2),)^{2}}$ X 100\% \\
& Januari & 249 & 249 & 0 & 0,8 \\
& Februari & 249 & 249 & 2 & 0,0 \\
& Maret & 249 & 251 & 0 & 0,8 \\
& April & 251 & 252 & 2 & 0,4 \\
& Mei & 252 & 256 & 1 & 3,5 \\
& Juni & 256 & 252 & 9 & 1,4 \\
Juli & 252 & 253 & 6 & 0,8 \\
& Agustus & 253 & 255 & 4 & 0,0 \\
& September & 255 & 258 & 2 & 0,4 \\
& Oktober & 258 & 258 & 0 & 0,0 \\
& November & 258 & 257 & 1 & 10,6 \\
Desember & 257 & 259 & 0 &
\end{tabular}

Sumber: Data Personalia Rumah Sakit Bali Royal Hospital, 2018

Tabel 1menunjukan bahwa selama tahun 2017 sejak bulan Januari sampai bulan Desember, tingkat turnover pada Rumah Sakit Bali Royal Hospital tergolong cukup tinggi. Selama satu tahun terakhir, jumlah karyawan yang keluar sebanyak 27 orang dan turnover tertinggi terjadi pada bulan Juni, dimana 9 orang karyawan keluar dari perusahaan dengan berbagai alasan. Gillies (1989) menyatakan perputaran karyawan dikatakan normal berkisar antara 5-10 persen pertahun dan dikatakan tinggi apabila lebih dari 10 persen pertahun. 
Berdasarkan data yang ada, tingkat turnover Bali Royal Hospital menunjukan angka di atas batas wajarnya. Tingginya turnover rate dari Rumah Sakit Bali Royal Hospital dapat diketahui dari data turnover tahun 2017 sebesar 10,6 persen, hal ini berarti Rumah Sakit BROS dikatakan memiliki permasalahan perpuataran karyawan yang tinggi. Menurut Jehanzeb et al.(2013) terdapat tiga indikator untuk mengukur turnover intention yang pertama adalah pikiran untuk keluar, dimana situasi di dalam perusahaan dirasa kurang nyaman yang menyebabkan karyawan memiliki pikiran untuk keluar dari perusahaan, kedua adalah keinginan untuk mencari lowongan pekerjaan lain merupakan ketidakmampuan perusahaan untuk memenuhi kebutuhan karyawannya sehingga memicu keinginan karyawan untuk mencari lowongan pekerjaan lain, dan yang terakhir adalah adanya keinginan karyawan untuk meninggalkan organisasi dalam beberapa bulan kedepan. Sutanto dan Gunawan(2013) menyatakan ada banyak penyebab terjadinya turnover intention antara lain stres kerja, lingkungan kerja, kepuasan kerja, komitmen organisasional dan lain sebagainya yang dialami oleh karyawan.

Karyawan dapat menilai seberapa puas atau tidak puas dirinya terhadap pekerjaannya. Semakin tinggi penilaian terhadap kegiatan dirasakan sesuai dengan keinginan individu, maka semakin tinggi kepuasannya terhadap kegiatan tersebut(Retnaningrum dan Musadieq, 2016). Kepuasan kerja juga dapat digambarkan memiliki sikap positif terhadap pekerjaan pada diri seseorang. Kepuasan kerja merupakan suatu keadaan yang berkaitan dengan reaksi emosional dari persepsi seseorang yang telah mendapatkan kebutuhan dan permintaan yang 
diinginkannya dari pekerjaan yang dia lakukan(Dizgah et al., 2012). Ketika karyawan merasakan kepuasan dalam bekerja, pastinya karyawan tersebut akan berupaya semaksimal mungkin dengan seluruh kemampuan yang dimilikinya untuk menyelesaikan tugasnya. Akan tetapi, tidak semua karyawan selalu mendapat kepuasan kerja yang mereka inginkan. Karyawan akan merasa cemas, tidak semangat, tidak bisa menikmati pekerjaan, dan tidak betah dengan pekerjaannya yang sekarang. Adanya hubungan negatif kepuasan kerja terhadap turnover intention dimana semakin kepuasan kerja meningkat maka turnover intention menurun sehingga kinerja perusahaan dapat ditingkatkan(Chenet al., 2010).

Stres kerja juga dapat berpengaruh terhadap turnover intentionselain faktor kepuasan kerja. Hasil penelitian yang dilakukan oleh Siddiqui dan Jamil(2015)menunjukkan bahwa stres kerja merupakan salah satu faktor utama yang mempengaruhi turnover intention karyawan.Menurut Nursyamsi(2012)stres kerja adalah konseptualisasi seorang individu dalam reaksi kerja terhadap karakteristik lingkungan yang akan dihadapi oleh karyawan, termasuk di dalamnya adalah berupa ancaman yang kemungkinannya juga akan ditemui karyawan dalam bekerja pada suatu organisasi.. Stres pada tahap yang parah dapat membuat karyawan menjadi sakit atau bahkan mengundurkan diri(Manurung dan Ratnawati, 2012). Karyawan sering kali dihadapkan dengan berbagai macam masalah di dalam maupun di luar perusahaan sehingga sangat mungkin bagi mereka untuk terkena stres. Stres yang berlebihan tidak mampu ditolelir karena individu tersebut kehilangan kemampuan untuk mengendalikan dirinya secara utuh. Akibatnya mereka tidak dapat lagi mengambil keputusan - keputusan secara 
tepat dan perilakunya menjadi terganggu. Dampak lain yang terjadi adalah sakit secara fisik, putus asa, sering absen dan lain - lain. Selama tingkat stres belum teratasi, maka tingkat produktivitas/prestasi kerja cendrung menurun drastis. Dalam Penelitian Arshadi dan Damiri(2013)menemukan bahwa stres kerja berhubungan positif dengan turnover intentions.

Stres di lingkungan kerja juga mempengaruhi emosi kepuasan kerja karyawan yang pada akhirnya timbul keputusan untuk berhenti dari pekerjaan. Semakin tinggi stres kerja yang dialami karyawan, maka kepuasan kerja yang dirasakan akan menurun, hal tersebutlah yang menyebabkan munculnya keinginan karyawan untuk berhenti dari perusahaan. Hal ini sesuai dengan hasil penelitian sebelumnya yang dilakukan olehIndrayani(2012) danBasri(2017) yang menyatakan bahwa apabila stres kerja karyawan tinggi, maka kepuasan karyawan akan menurun dan akan meningkatkan turnover intention karyawan.

Karyawan yang merasa puas dengan apa yang diperolehnya dari organisasi, akan memberikan lebih dari apa yang diharapkan. Seiring dengan perubahan kondisi lingkungan perusahaan dalam situasi yang tidak pasti mendorong perusahaan untuk merespon dengan cepat dan beradaptasi dengan lingkungan pasar yang penuh dengan persaingan. Perubahan ini secara langsung maupun tidak langsung dapat mempengaruhi kepuasan kerja yang pada akhirnya dapat menimbulkan niat untuk pindah bagi karyawan yang pada akhirnya juga dapat menimbulkan kepindahan yang sebenarnya. Stres kerja yang dialami karyawan juga dapat membuat karyawan tidak merasa puas dengan pekerjaannya dan juga menjadi alasan mengapa mereka ingin berpindah. 
E-Jurnal Manajemen, Vol. 8, No. 6, 2019 :3646-3673 
Teori yang digunakan dalam penelitian ini adalah social exchange theory. Social Exchange Theorymenunjukkan bahwa orang yang merasa bahwa ia/dia mendapat manfaat dari seseorang akan merasa berkewajiban untuk membayar melalui perilaku yang positif, sikap, upaya dan pengabdian. Beberapa penelitian telah dilakukan sebelumnya mengenai stres kerja yang merupakan faktor penting yang dapat mempengaruhi turnover intention. Ahmad et al.(2012)dalam penelitiannya mendapatkan hasil, bahwa karyawan yang mengalami stres kerja tinggi memiliki niat yang tinggi juga untuk berhenti dari pekerjaannya. Hasil penelitian Yuda dan Ardana(2017)yang mengemukakan bahwa stres kerja memiliki pengaruh positif terhadap turnover intention. Penelitian Siddiqui dan Jamil(2015)menunjukkan bahwa terdapat hubungan positif dan langsung antara stres kerja dan turnover intention, sehingga peningkatan stres kerja akan meningkatkan pula keinginan berpindah kerja. Hasil yang sama didapatkan Mosadeghrad et al.(2012)dan Chandio et al.(2013), bahwa stres kerja bepengaruh positif terhadap turnoverintention karyawan, dimana semakin tinggi tingkat stres kerja maka semakin tinggi juga tingkat turnover intention yang terjadi. Berdasarkan hasil penelitian-penelitian sebelumnya, maka dapat ditarik rumusan hipotesis sebagai berikut.

$\mathrm{H}_{1}$ : Stres kerja berpengaruh positif signifikan terhadap turnover intention

Beberapa penelitian telah dilakukan mengenai stres kerja yang berpengaruh terhadap kepuasan kerja. Iqbal dan Waseem(2012)melakukan penelitian mengenai pengaruh stres kerja terhadap kepuasan kerja karyawan., hasil penelitian menunjukan bahwa hubungan negatif antara stres kerja dengan kepuasan kerja. 
Hasil penelitian Faqihudin dan Gunistiyo(2010)diketahui stres kerja mempunyai pengaruh signifikan dan negatif terhadap kepuasan kerja karyawan. Sheraz et al.(2014)dan jugaBasri(2017), dalam penelitiannya juga menyatakan bahwa stres kerja berpengaruh negatif dan signifikan terhadap kepuasan kerja. Penelitian yang dilakukan oleh Karambut dan Noormijati(2012)menyatakan stres kerja berpengaruh negatif dan signifikan terhadap kepuasan kerja, semakin tinggi stres kerja yang dirasakan maka kepuasan kerja semakin rendah dan juga sebaliknya. Berdasarkan hasil penelitian-penelitian sebelumnya, maka dapat ditarik rumusan hipotesis sebagai berikut.

$\mathrm{H}_{2}$ : Stres kerja berpengaruh negatif signifikan terhadap kepuasan kerja

Penelitian yang telah dilakukan sebelumnya mengenai kepuasan kerja yang merupakan faktor yang sangat penting yang berpengaruh terhadap turnover intention. Menurut Ahmad et al.(2012)dalam studinya menemukan bahwa kepuasan kerja memiliki pengaruh yang kuat terhadap turnover intention, dimana kepuasan kerja berpengaruh negatif terhadap turnover intention. Salleh et al.(2012)serta Warshawsky dan Havens(2015)dalam penelitiannya menemukan bahwa adanya pengaruh negatif dan signifikan antara kepuasan kerja dan turnover intention. Hasil penelitian Mahdi et al. (2012)juga menyatakan adanya pengaruh negatif antara kepuasan kerja dengan turnover intention, dimana karyawan yang mencapai kepuasan kerja akan berusaha untuk tetap berada di dalam perusahan. Pernyataan tersebut diperkuat oleh hasil temuan dari Kabungaidze dan Mahlatshana(2013)yang menyatakan bahwa karyawan yang tidak puas dengan pekerjaan mereka dan sikap positif terhadap turnover intention, jadi semakin 
tinggi tingkat kepuasan kerja karyawan maka semakin rendah tingkat turnover intention karyawan. Berdasarkan hasil penelitian-penelitian sebelumnya, maka dapat ditarik rumusan hipotesis sebagai berikut.

$\mathrm{H}_{3}$ : Kepuasan kerja berpengaruh negatif sigifikan terhadap turnover intention

Beberapa penelitian telah dilakukan mengenai kepuasan kerja dapat memediasi hubungan antara stres kerja terhadap turnover intention. Indrayani (2012)menyimpulkan bahwa kepuasan kerja berpengaruh signifikan sebagai variabel mediasi antara hubungan stres kerja dengan intensi keluar karyawan. Basri (2017)dalam penelitiannya mengatakan bahwa kepuasan kerja memediasi pengaruh stres kerja terhadap turnover intentions.Banyak penelitian menunjukkan bahwa kepuasan kerja memediasi secara parsial hubungan antara stres kerja dan turnover intention karyawan, hal tersebut selaras dengan penelitian yang dilakukan oleh Sheraz et al.(2014)yang mengatakan bahwa banyak hasil penelitian yang menunjukkan bahwa stres kerja memiliki dampak negatif pada kepuasan kerja dan kepuasan kerja secara signifikan berhubungan negatif dengan turnover intention. Berdasarkan hasil penelitian-penelitian sebelumnya, maka dapat ditarik rumusan hipotesis sebagai berikut.

$\mathrm{H}_{4}$ : Kepuasan kerja memediasi hubungan antara stres kerja dengan turnover intention

\section{METODE PENELITIAN}

Lokasi penelitian dilakukan di Rumah Sakit Bali Royal Hospital di Jalan Tantular No.6 Renon Denpasar. Alasan yang mendasari pemilihan rumah sakit ini sebagai lokasi penelitian adalah karena ditemukannya masalah mengenai turnover 
intention seperti yang sudah dijelaskan pada bagian latar belakang. Populasi dalam penelitian ini adalah seluruh karyawan tetap di Rumah Sakit Bali Royal Hospital yang berjumlah 259 orang. Dalam penelitian ini, metode penentuan sampel yang digunakan yaitu proportionate stratified random sampling.

Dalam menentukan jumlah sampel dari sebuah populasi, peneliti menggunakan rumus Slovin, yaitu.

$$
\begin{gathered}
\frac{\mathrm{N}}{1+\mathrm{Ne}^{2}}=\ldots . . \\
\frac{259}{1+259 \times 0,10^{2}}=72,14
\end{gathered}
$$

Keterangan:

$$
\begin{array}{ll}
\mathrm{n} & =\text { sampel } \\
\mathrm{N} & =\text { populasi } \\
\mathrm{e} & =\text { error. Pada penelitian ini error ditetapkan } 10 \%
\end{array}
$$

Dari perhitungan di atas, maka sampel yang digunakan berjumlah 72,14 yang kemudian dibulatkan menjadi 72 responden.

Tabel 2.

Proporsi Jumlah Sampel

\begin{tabular}{lcc}
\hline \multicolumn{1}{c}{ Divisi } & Proporsi Sampel & Jumlah Sampel \\
\hline Exceutive Office & $4 / 259 \times 72$ & 1 \\
Penunjang Medis & $39 / 259 \times 72$ & 11 \\
Pelayanan Medis & $12 / 259 \times 72$ & 3 \\
Keperawatan & $89 / 259 / 72$ & 25 \\
Sumber Daya Manusia (SDM) & $15 / 259 \times 72$ & 4 \\
Hubungan Pelanggan & $21 / 259 \times 72$ & 6 \\
Pemasaran & $17 / 259 \times 72$ & \multicolumn{2}{c}{5} \\
Pengembangan Bisnis & $10 / 259 \times 72$ & 3 \\
Umum & $22 / 259 \times 72$ & 6 \\
Keungan & $17 / 259 \times 72$ & \multicolumn{2}{c}{5} \\
Akunting & $13 / 259 \times 72$ & 4 \\
& & $\mathbf{7 2}$ \\
\hline
\end{tabular}

Sumber: Data diolah, 2018 
Teknik analisis data yang digunakan dalam penelitian ini adalah Teknik analisis jalur. Analisis jalur (path analysis) adalah perluasan dari analisis regresi linier berganda, dimana pengembangan disini berupa penerapan variabel mediasi. Variabel mediasi merupakan variabel yang memiliki peran memediasi hubungan antara suatu variabel dengan vaiabel lainnya.

Persamaan Sub-Struktural 1

$$
\mathrm{Y}_{1}=\beta_{2 \mathrm{a}} \mathrm{X}+\mathrm{e}_{1}
$$

Persamaan Sub-Struktural 2

$$
\mathrm{Y}_{2}=\beta_{1} \mathrm{X}+\beta_{2 \mathrm{~b}} \mathrm{M}+\mathrm{e}_{2}
$$

Keterangan:

$$
\begin{aligned}
& \mathrm{X}=\text { Stres Kerja } \\
& \mathrm{M}=\text { Kepuasan kerja } \\
& \mathrm{Y} \quad=\text { Turnover Intention } \\
& \mathrm{a} \quad=\text { Nilai konstanta } \\
& \beta_{2 \mathrm{a}} \quad=\text { Koefesien regresi variabel stres kerja pada kepuasan kerja } \\
& \beta_{1} \quad=\text { Koefesien regresi variabel stres kerja pada turnover intention } \\
& \beta_{2 \mathrm{~b}}=\text { Koefesien regresi variabel kepuasan kerja pada turnover } \\
& \text { intention } \\
& \mathrm{e}_{1}, \mathrm{e}_{2}=\text { Jumlah varian yang tidak diteliti dalam model }
\end{aligned}
$$

Uji Sobel digunakan dengan menguji kekuatan pengaruh tidak langsung variabel. Stres Kerja (X) terhadap variabel Turnover Intention (Y) melalui variabel Kepuasan Kerja (M). Pengaruh tidak langsung dari variabel stres kerja (X) terhadap variabel turnover intention (Y) melalui variabel kepuasan kerja (M) dihitung dengan cara mengkalikan koefisien jalur $\mathrm{X}$ terhadap $\mathrm{M}$ (a) dengan koefisien jalur M terhadap Y (b) atau ab. Standar error koefisien a dan b ditulis dengan Sa dan Sb. Besarnya standar error tidak langsung (indirect effect) Sab. 
Standar error tidak langsung (indirect effect) Sab dihitung dengan rumus sebagai berikut.

$$
\mathrm{Sab}=\sqrt{ } \mathrm{b}^{2} \mathrm{Sa}^{2}+\mathrm{a}^{2} \mathrm{Sb}^{2}+\mathrm{Sa}^{2} \mathrm{Sb}^{2}
$$

Untuk menguji signifikansi pengaruh tidak langsung maka nilai $\mathrm{z}$ dari koefisien ab dihitung dengan rumus sebagai berikut.

$$
z=\frac{\mathrm{a}}{\mathrm{s}}
$$

Keterangan:

$$
\begin{aligned}
& \mathrm{Sab}=\text { besarnya standar error tidak langsung } \\
& \mathrm{Sa} \quad=\text { standar error koefisien a } \\
& \mathrm{Sb} \quad=\text { standar error koefisien } \mathrm{b} \\
& \text { a } \quad=\text { koefisien jalur } \mathrm{X} \text { terhadap } \mathrm{M} \\
& \mathrm{b}=\text { koefisien jalur M terhadap } \mathrm{Y} \\
& \mathrm{ab} \quad=\text { hasil kali koefisien jalur X terhadap koefisien jalur } \mathrm{M} \text { (a) } \\
& \text { dengan jalur } \mathrm{M} \text { terhadap } \mathrm{Y}(\mathrm{b})
\end{aligned}
$$

\section{HASIL DAN PEMBAHASAN}

Hasil penelitian yang dilakukan terhadap karyawan Rumah Sakit Bali Royal Hospital, maka dapat diketahui gambaran karakteristik responden yang meliputi empat aspek, yaitu jenis kelamin, tingkat umur, tingkat pendidikan serta masa kerja. Kuesioner yang disebarkan kepada responden sebanyak 72 kuesioner. Jadi, jumlah responden yang digunakan pada penelitian ini adalah sebanyak 72 orang. Deskripsi mengenai karakteristik responden penelitian disajikan pada Tabel 3.

Berdasarkan Tabel 3, menunjukkan bahwa responden pada penelitian sebagian besar berjenis kelamin perempuan dengan persentase sebesar 75 persen yang berjumlah 54 orang. Sedangkan karakteristik responden berdasarkan tingkat 
usia menunjukkan bahwa karyawan yang bekerja di Rumah Sakit Bali Royal Hospital sebagian besar berumur antara 21 sampai 30 tahun sebanyak 47,22 persenyang berjumlah 34 orang. Hal ini menunjukkan bahwa karyawan yang bekerja di Rumah Sakit Bali Royal Hospital tergolong karyawan yang berusia produktif.

Tabel 3.

Karakteristik Responden

\begin{tabular}{|c|c|c|c|}
\hline \multirow{2}{*}{ No } & \multirow{2}{*}{ Jenis Kelamin } & \multicolumn{2}{|c|}{ Jumlah } \\
\hline & & Orang & Persentase (\%) \\
\hline 1 & Laki-Laki & 18 & 25 \\
\hline 2 & Perempuan & 54 & 75 \\
\hline No & Tingkat Umur & \multicolumn{2}{|c|}{ Jumlah } \\
\hline & (Tahun) & Orang & Persentase (\%) \\
\hline 1 & $<21$ & 0 & 0 \\
\hline 2 & $21-30$ & 34 & 47,22 \\
\hline 3 & $31-40$ & 29 & 40,28 \\
\hline 4 & $>40$ & 9 & 12,50 \\
\hline No & Tingkat Pendidikan & \multicolumn{2}{|c|}{ Jumlah } \\
\hline 1 & SMA & 5 & 6,94 \\
\hline 2 & Diploma & 12 & 16,67 \\
\hline 3 & Sedang menempuh S1 & 8 & 11,11 \\
\hline 4 & Lulus S1 & 40 & 55,56 \\
\hline 5 & Sedang menempuh S2 & 1 & 1,39 \\
\hline 6 & Lulus S2 & 6 & 8,33 \\
\hline 7 & S3 & 0 & 0,00 \\
\hline No & Masa Kerja & \multicolumn{2}{|c|}{ Jumlah } \\
\hline 100 & (Tahun) & Orang & Persentase (\%) \\
\hline 1 & $1-2$ & 7 & 9,72 \\
\hline 2 & $2-3$ & 8 & 11,11 \\
\hline 3 & $3-4$ & 16 & 22,22 \\
\hline 4 & $>4$ & 41 & 56,94 \\
\hline
\end{tabular}

Karakteristik responden berdasarkan tingkat pendidikan menunjukkan bahwa karyawan di Rumah Sakit Bali Royal Hospital didominasi oleh karyawan yang berpendidikan S1 sebanyak 55,56 persen yang berjumlah 40 orang. Ini menunjukkan bahwa karyawan di Rumah Sakit Bali Royal Hospital merupakan karyawan yang berpendidikan. Untuk karakteristik responden berdasarkan masa kerja menunjukkan bahwa karyawan di Rumah Sakit Bali Royal Hospital 
didominasi karyawan yang sudah bekerja lebih dari 4 tahun sebanyak 56,94 persen yang berjumlah 41 orang.

Instrumen dikatakan valid jika korelasi antar skor faktor dengan skor total bernilai positif dan nilainya lebih dari sama dengan 0,30 ( $\mathrm{r} \geq 0,3)$. Tabel 4 menyajikan hasil uji validitas instrumen penelitian.

Tabel 4.

Hasil Uji Validitas

\begin{tabular}{|c|c|c|c|c|}
\hline No & Variabel & $\begin{array}{c}\text { Item } \\
\text { Pertanyaan }\end{array}$ & $\begin{array}{c}\text { Korelasi Item } \\
\text { Total }\end{array}$ & Keterangan \\
\hline \multirow{5}{*}{1} & \multirow{5}{*}{ Stres Kerja (X) } & $\mathrm{X} 1$ & 0,841 & Valid \\
\hline & & $\mathrm{X} 2$ & 0,694 & Valid \\
\hline & & $\mathrm{X} 3$ & 0,421 & Valid \\
\hline & & $\mathrm{X} 4$ & 0,467 & Valid \\
\hline & & X5 & 0,507 & Valid \\
\hline \multirow{5}{*}{2} & \multirow{5}{*}{ Kepuasan Kerja (M) } & M1 & 0,712 & Valid \\
\hline & & M2 & 0,601 & Valid \\
\hline & & M3 & 0,746 & Valid \\
\hline & & M4 & 0,614 & Valid \\
\hline & & M5 & 0,719 & Valid \\
\hline \multirow{3}{*}{3} & & Y1 & 0,834 & Valid \\
\hline & Turnover Intention $(\mathrm{Y})$ & $\mathrm{Y} 2$ & 0,814 & Valid \\
\hline & & Y3 & 0,885 & Valid \\
\hline
\end{tabular}

Sumber: Data diolah, 2018

Tabel 4 menunjukan bahwa setiap butir pertanyaan pada kuisioner memiliki skor lebih dari sama dengan 0,30. Hasil uji validitas menghasilkan korelasi terkecil sebesar 0,421 dan korelasi yang terbesar yaitu 0,885. Uji validitas menunjukan bahwa kuisioner layak digunakan dalam penelitian ini.

Uji reliabilitas menunjukan sejauh mana suatu alat pengukur dapat dipercaya atau dapat diandalkan. Suatu instrumen dikatakan reliabel, jika instrumen tersebut memiliki nilai Alpha Cronbach lebih dari sama dengan 0,60 (r 20,6). Tabel 5 menyajikan hasil uji reliabilitas instrumen penelitian.

Tabel 5 menunjukkan bahwa instrumen penelitian yaitu stres kerja, kepuasan kerja dan turnover intention memiliki koefisien Cronbach's Alpha lebih 
dari sama dengan 0,60 . Hal ini berarti semua instrumen reliabel sehingga dapat digunakan untuk melakukan penelitian ini.

Tabel 5.

Hasil Uji Reliabilitas

\begin{tabular}{ccc} 
Variabel & Cronbach's Alpha & Keterangan \\
& & \\
\hline Stres Kerja (X) & 0,734 & Reliabel \\
Kepuasan Kerja (M) & 0,767 & Reliabel \\
Turnover Intention (Y) & 0,843 & Reliabel \\
\hline
\end{tabular}

Sumber: Data diolah, 2018

Perhitungan koefisien path dilakukan dengan analisis regresi melalui software SPSS 17.0 for Windows, diperoleh hasil yang ditunjukkan pada tabel sebagai berikut.

Tabel 6.

Hasil Analisis Jalur Persamaan Regresi 1

\begin{tabular}{|c|c|c|c|c|c|}
\hline \multirow[t]{2}{*}{ Model } & \multicolumn{2}{|c|}{$\begin{array}{c}\text { Unstandardized } \\
\text { Coefficients }\end{array}$} & \multirow{2}{*}{$\begin{array}{c}\text { Standardized } \\
\text { Coefficients } \\
\text { Beta }\end{array}$} & \multirow[t]{2}{*}{$\mathbf{T}$} & \multirow[t]{2}{*}{ Sig. } \\
\hline & B & Std. Error & & & \\
\hline (Constant) & 23,829 & 1,106 & & 21,550 & 0,000 \\
\hline Stres Kerja $(\mathrm{X})$ & $-0,527$ & 0,078 & $-0,630$ & $-6,795$ & 0,000 \\
\hline $\mathrm{R} 2$ & & & & & 0,397 \\
\hline F Hitung & & & & & 46,179 \\
\hline Sig. F & & & & & 0,000 \\
\hline
\end{tabular}

Hasil analisis jalur substruktural 1 seperti yang disajikan pada Tabel 4.7 maka persamaan strukturalnya adalah sebagai berikut.

$\mathrm{Y}_{1}=\beta_{2} \mathrm{aX}+\mathrm{e}_{1}$

$Y_{1}=-0,630 X$

Hasil analisis jalur substruktural 2 seperti yang disajikan pada Tabel 7 maka persamaan strukturalnya adalah sebagai berikut.

$$
\mathrm{Y}_{2}=\beta_{1} \mathrm{X}+\beta_{2 \mathrm{~b}} \mathrm{M}+\mathrm{e}_{2}
$$




$$
\mathrm{Y}_{2}=0,269 \mathrm{X}-0,434 \mathrm{M}
$$

Berdasarkan model substruktur 1 dan substruktur 2, maka dapat disusun model diagram jalur akhir. Sebelum menyusun diagram jalur akhir, terlebih dahulu dihitung nilai standar error sebagi berikut.

$$
\begin{aligned}
& \mathrm{Pe}_{\mathrm{i}}=\sqrt{1-R^{2}} \ldots \ldots \ldots \ldots \ldots \ldots \ldots \ldots \ldots \\
& \mathrm{Pe}_{1}=\sqrt{1-R 1^{2}}=\sqrt{1-0,397}=0,777 \\
& \mathrm{Pe}_{2}=\sqrt{1-k 2^{2}}=\sqrt{1-0,408}=0,769
\end{aligned}
$$

Tabel 7.

Hasil Analisis Jalur Persamaan Regresi 2

\begin{tabular}{lrrrrr}
\multicolumn{1}{c}{ Model } & \multicolumn{1}{c}{$\begin{array}{c}\text { Unstandardized } \\
\text { Coefficients }\end{array}$} & $\begin{array}{l}\text { Standardized } \\
\text { Coefficients }\end{array}$ & \multicolumn{1}{c}{ T } & Sig. \\
& \multicolumn{1}{c}{ B } & Std. Error & Beta & & \\
\hline (Constant) & 12,305 & 2,770 & & 4,443 & 0,000 \\
Stres Kerja (X) & 0,204 & 0,091 & 0,269 & 2,254 & 0,027 \\
Kepuasan Kerja (Y) & $-0,394$ & 0,108 & $-0,434$ & $-3,639$ & 0,001 \\
R2 & & & & & 0,408 \\
F Hitung & & & & & 23,781 \\
Sig. F & & & & & 0,000 \\
\hline
\end{tabular}

Sumber: Data diolah, 2018

Berdasarkan perhitungan pengaruh error $\left(\mathrm{Pe}_{\mathrm{i}}\right)$, didapatkan hasil pengaruh error $\left(\mathrm{Pe}_{1}\right)$ sebesar 0,777 dan pengaruh error $\left(\mathrm{Pe}_{2}\right)$ sebesar 0,769. Hasil koefisien determinasi total adalah sebagai berikut.

$$
\begin{aligned}
\mathrm{R}_{\mathrm{m}}^{2} & =1-\left(\mathrm{Pe}_{1}\right)^{2}\left(\mathrm{Pe}_{2}\right)^{2} \ldots . \\
& =1-(0,777)^{2}(0,769)^{2} \\
& =1-(0,603)(0,591) \\
& =1-0,356=0,644
\end{aligned}
$$


Nilai determinasi total sebesar 0,644 mempunyai arti bahwa sebesar 64,4 persen variasai turnover intention karyawan dipengaruhi oleh variasi stres kerja dan variasi kepuasan kerja, sedangkan sisanya sebesar 35,6 persen dijelaskan oleh faktor lain yang tidak dimasukan ke dalam model.

Hasil analisis pengaruh stres kerja terhadap turnover intention diperoleh nilai Sig. $\mathrm{t}$ sebesar 0,027 dengan nilai koefisien beta 0,269. Nilai Sig. t 0,027 $\leq$ 0,05 mengindikasikan bahwa $\mathrm{H}_{0}$ ditolak dan $\mathrm{H}_{1}$ diterima. Hasil ini mempunyai arti bahwa stres kerja berpengaruh positif signifikan terhadap turnover intention.

Hasil analisis pengaruh stres kerja terhadap kepuasan kerja diperoleh nilai Sig. $\mathrm{t}$ sebesar 0,000 dengan nilai koefisien beta -0,630. Ini berarti bahwa Sig. $\mathrm{t}$ $0,000 \leq 0,05$ mengindikasikan bahwa $\mathrm{H}_{0}$ ditolak dan $\mathrm{H}_{1}$ diterima. Hasil ini mempunyai arti bahwa stres kerja berpengaruh negatif signifikan terhadap kepuasan kerja.

Hasil analisis pengaruh kepuasan kerja terhadap turnover intention diperoleh nilai Sig. $\mathrm{t}$ sebesar 0,001 dengan nilai koefisien beta -0,434. Ini berarti bahwa Sig. t 0,001 $\leq 0,05$ mengindikasikan bahwa $\mathrm{H}_{0}$ ditolak dan $\mathrm{H}_{1}$ diterima. Hasil ini mempunyai arti bahwa kepuasan kerja berpengaruh negatif signifikan terhadap turnover intention.

Besarnya pengaruh langsung dan pengaruh tidak langsung serta pengaruh total antar variabel. Perhitungan pengaruh antar variabel dirangkum dalam tabel 8 sebagai berikut.

Tabel 8.

Rangkuman Hasil Uji

\begin{tabular}{llll} 
Pengaruh Pengaruh Pengaruh Tidak Langsung Melalui Pengaruh \\
\hline
\end{tabular}




\begin{tabular}{|c|c|c|c|}
\hline Variabel & Langsung & Kepuasan Kerja (Y) $(\beta 2 \times \beta 3)$ & Total \\
\hline $\mathrm{X} \longrightarrow \mathrm{M}$ & $-0,630$ & - & $-0,630$ \\
\hline $\mathrm{X} \longrightarrow \mathrm{Y}$ & 0,269 & 0,273 & 0,542 \\
\hline $\mathrm{M} \longrightarrow \mathrm{Y}$ & $-0,434$ & - & $-0,434$ \\
\hline \multicolumn{4}{|c|}{ Sumber : Data diolah, 2018} \\
\hline Keterangan & $\begin{array}{l}\mathrm{X}: \text { Stres Ker } \\
\mathrm{M}: \text { Kepuasai } \\
\mathrm{Y}: \text { Turnover }\end{array}$ & & \\
\hline
\end{tabular}

Uji Sobel dirumuskan dengan persamaan berikut dan dapat dihitung dengan menggunakan aplikasi Microsoft Excel 2007. Bila nilai kalkulasi Z lebih besar dari 1,96 (dengan tingkat kepercayaan 95 persen), maka variabel mediator dinilai secara signifikan memediasi hubungan antara variabel terikat dan variabel bebas.

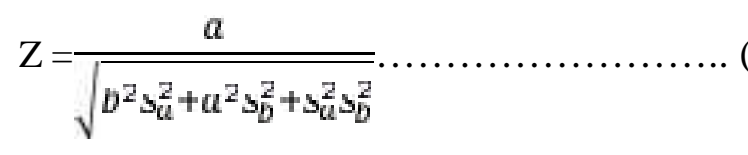

Keterangan :

$\begin{array}{ll}\mathrm{a} & =-0,527 \\ \mathrm{Sa} & =0,078 \\ \mathrm{~b} & =-0,398 \\ \mathrm{Sb} & =0,108\end{array}$

Sumber : Lampiran 6

$$
\begin{aligned}
& Z=\frac{-0,527 \times(-0,398)}{\sqrt{\left(-0,398^{2}\right)\left(0,078^{2}\right)+\left(-0.527^{2}\right)\left(0,108^{2}\right)+\left(0,078^{2}\right)\left(0,108^{2}\right)}} \\
& Z=\frac{0,209746}{\sqrt{0,00096373+0,003239431+0,00007096}} \\
& Z=\frac{0,209746}{0,065376791} \\
& Z=3,21
\end{aligned}
$$


Berdasarkan hasil hasil perhitungan menunjukkan bahwa hasil tabulasi $\mathrm{Z}=$ 3,21> 1,96 yang berarti variabel mediator yakni kepuasan kerja dinilai secara signifikansi memediasi hubungan antara stres kerja terhadap turnover intention karyawan.

Berdasarkan penngujian hipotesis variabel stres kerja terhadap turnover intention, diperoleh hasil bahawa teori yang digunakan dalam penelitian ini yaitu social exchange theory terkonfirmasi. Teori tersebut menunjukan bahwa orang yang merasa bahwa ia/dia mendapat manfaat dari organisasi akan merasa berkewajiban untuk membayar melalui perilaku positif, sikap, upaya dan pengabdian, hal tersebut sesuai dengan penelitian ini yang mendapatkan hasil Ho ditolak dan H1 diterima. Hasil ini mempunyai arti bahwa stres kerja berpengaruh positif signifikan terhadap turnover intention. Ini berarti semakin tinggi tingkat stres kerja yang dirasakan karyawan maka semakin besar pula resiko karyawan untuk keluar dari perusahaan.

Tingkat turnover karyawan Rumah Sakit BROS disebabkan oleh adanya stres kerja yang dirasakan karyawan. Dalam hal ini tingkat stres kerja sebagian besar disebabkan karena pekerjaan yang diberikan bersifat khusus dan juga adanya desakan waktu dalam menyelesaikan pekerjaan, sehingga menyebabkan karawan memiliki keinginan untuk mencari pekerjaan di tampat lain. Sebaiknya tingkat stres kerja perlu diturunkan untuk memperkecil tingginya tingkat turnover intention pada Rumah Sakit BROS. Penelitian ini sesuai dengan penelitian Ahmad et al.(2012)dalam penelitiannya mendapatkan hasil bahwa karyawan yang mengalami stres kerja tinggi memiliki niat yang tinggi juga untuk berhenti 
dari pekerjaannya. Hasil ini juga didukung penelitian yang dilakukan oleh Mosadeghrad et al.(2012)dan Chandio et al.(2013), bahwa stres kerja bepengaruh positif terhadap turnoverintention karyawan, dimana semakin tinggi tingkat stres kerja maka semakin tinggi juga tingkat turnover intention yang terjadi.

Berdasarkan penngujian hipotesis variabel stres kerja terhadap kepuasan kerja, diperoleh hasil bahawa teori yang digunakan dalam penelitian ini yaitu social exchange theory terkonfirmasi. Teori tersebut menunjukan bahwa orang yang merasa bahwa ia/dia mendapat manfaat dari organisasi akan merasa berkewajiban untuk membayar melalui perilaku positif, sikap, upaya dan pengabdian, hal tersebut sesuai dengan penelitian ini yang mendapatkan hasil Ho ditolak dan $\mathrm{H} 1$ diterima. Hasil ini mempunyai arti bahwa stres kerja berpengaruh negatif signifikan terhadap kepuasan kerja. Ini berarti semakin tinggi tingkat stres kerja yang dirasakan karyawan maka semakin rendah tingkat kepuasan kerja mereka di dalam perusahaan.

Tingkat kepuasan kerja Rumah Sakit BROS dipengaruhi oleh adanya stres kerja yang dirasakan karyawan. Dalam hal ini tingkat stres kerja sebagian besar disebabkan karena pekerjaan yang diberikan bersifat khusus dan juga adanya desakan waktu dalam menyelesaikan pekerjaan. Sebaiknya tingkat stres kerja perlu diturunkan untuk meningkatkan tingkat kepuasan kerja yang dirasakan karyawan pada Rumah Sakit BROS. Peneltian ini sejalan dengan penelitian yang dilakukan oleh Iqbal dan Waseem(2012)mengenai pengaruh stres kerja terhadap kepuasan kerja karyawan., hasil penelitian menunjukan bahwa hubungan negatif antara stres kerja dengan kepuasan kerja. Riset yang dilakukan oleh Karambut 
dan Noormijati(2012)juga mendapatkan hasil yang serupa dimana stres kerja berpengaruh negatif dan signifikan terhadap kepuasan kerja, semakin tinggi stres kerja yang dirasakan maka kepuasan kerja semakin rendah dan juga sebaliknya.

Berdasarkan penngujian hipotesis variabel kepuasan kerja terhadap turnover intention, diperoleh hasil bahawa teori yang digunakan dalam penelitian ini yaitu social exchange theory terkonfirmasi. Teori tersebut menunjukan bahwa orang yang merasa bahwa ia/dia mendapat manfaat dari organisasi akan merasa berkewajiban untuk membayar melalui perilaku positif, sikap, upaya dan pengabdian, hal tersebut sesuai dengan penelitian ini yang mendapatkan hasil Ho ditolak dan $\mathrm{H} 1$ diterima. Hasil ini mempunyai arti bahwa kepuasan kerja berpengaruh negatif signifikan terhadap turnover intention. Ini berarti semakin tinggi tingkat kepuasan kerja yang dirasakan karyawan akan dapat menurunkan keinginan karyawan untuk keluar dari perusahaanya.

Tingkat turnover intention Rumah Sakit BROS dipengaruhi oleh adanya kepuasan kerja yang dirasakan karyawan. Dalam hal ini tingkat kepuasan kerja sebagian besar disebabkan karena kurangnya pemberian penghargaan oleh pimpinan dan juga gaji yang diberikan tidak sesuai dengan beban kerja, sehingga menyebabkan karyawan memiliki keinginan untuk mencari pekerjaan di tampat lain. Sebaiknya tingkat kepuasan kerja karyawan perlu ditingkatkan untuk menurunkan tingkat turnover intention pada Rumah Sakit BROS. Penelitian ini sejalan dengan penelitian yang dilakukan oleh Sallehet al.(2012)yang menyatakan bahwa kepuasan kerja mempunyai hubungan yang negatif dengan turnover intention. Hasil penelitian Mahdi et al.(2012)juga menyatakan adanya pengaruh 
negatif antara kepuasan kerja dengan turnover intention, dimana karyawan yang mencapai kepuasan kerja akan berusaha untuk tetap berada di dalam perusahan.

Hasil uji sobel didapatkan bahwa secara signifikan kepuasan kerja memediasi pengaruh stres kerja terhadap turnover intention. Pengujian sebelumnya mendapatkan stres kerja berpengaruh signifikan pada turnover intention, stres kerja berpengaruh signifikan pada kepuasan kerja dan kepuasan kerja berpengaruh signifikan pada turnover intention, sehingga dapat dikatakan bahwa kepuasan kerja secara parsial memediasi pengaruh stres kerja terhadap turnover intention. Seperti yang dinyatakan oleh Basri(2017), dalam penelitiannya mengatakan bahwa kepuasan kerja memediasi pengaruh stres kerja terhadap turnover intentions. Hasil penelitian ini didukung olehIndrayani(2012), yang menyimpulkan bahwa kepuasan kerja berpengaruh signifikan sebagai variabel mediasi antara hubungan stres kerja dengan intensi keluar karyawan.

Hasil penelitian ini membuktikan bahwa turnover intention dipengaruhi oleh stres kerja dan kepuasan kerja. Manajemen perlu menurunkan tingkat turnover intention dengan memperhatikan tingkat stres kerja dan kepuasan kerja. Upaya yang dapat dilakukan perusahaan agar mampu mengendalikan permasalahan padaturnover intention tersebut adalah pihak manajemen rumah sakit hendaknya mampu mengurangi perasaan tertekan karyawannya, dengan memperhatikan waktu dan beban kerja yang diberikan, agar nantinya mampu mengurangi tingkat stres karyawan dalam menyelesaikan tugasnya dengan baik.

Pihak manajemen rumah sakit perlu memperhatikan cara memperlakukan karyawannya dan juga memperhatikan kesesuaian antara gaji dengan beban kerja 
yang diberikan, agar mereka merasa dihargai ketika sudah bekerja dengan baik, karena jika tingkat kepuasan kerja karyawan semakin tinggi, maka akan bisa mengurangi pemikiran karyawan untuk meninggalkan perusahaan. Berbagai kebijakan yang menyangkut tentang pengakuan prestasi, interaksi antara atasan dengan bawahan juga dirasa perlu ditingkatkan untuk meningkatkan kepuasan dari karyawannya.

Pihak manajemen rumah sakit hendaknya perlu mencegah karyawannya agar tidak sampai memiliki keinginan meninggalkan tempat bekerjanya, karena hal tersebut nantinya bisa menyebabkan karyawan benar-benar meningglkan perusahaan, yang bisa sangat merugikan kedepannya. Menjaga tingkat stres agar tetap rendah, memberikan motivasi dan dukungan kepada para karyawan merupakan cara yang bisa dilakukan perusahaan untuk merubah pola pikir karyawan agar tidak sampai memiliki keinginan untuk mencari pekerjaan di tempat lain.

\section{SIMPULAN}

Stres kerja berpengaruh positif dan signifikan terhadap turnover intention. Hal ini menunjukkan bahwa semakin tinggi tingkat stres kerja maka semakin tinggi pula tingkat turnover intention yang dirasakan karyawan perusahaan tersebut.

Stres kerja berpengaruh negatif dan signifikan terhadap kepuasan kerja. Hal ini menunjukkan bahwa semakin tinggi tingkat stres kerja maka semakin rendah kepuasan kerja yang dirasakan karyawan pada perusahaan tersebut. 
Kepuasan kerja berpengaruh negatif dan signifikan terhadap turnover intention. Hal ini menunjukkan bahwa semakin tinggi tingkat kepuasan kerja. karyawan maka semakin rendah turnover intention yang dirasakan karyawan pada perusahaan tersebut.Kepuasan kerja secara parsial memediasi pengaruh stres kerja terhadap turnover intention.

Pihak rumah sakit harus dapat mengendalikan tingkat stres karyawan untuk menurunkan turnover intention, hal tersebut dapat dilakukan dengan cara memperhatikan antara beban kerja yang diberikan dengan waktu diberikan dalam menyelesaikan pekerjaan, adanya variasi dalam pemberian pekerjaan karena karyawan cenderung merasa bosan apabila diberikan pekerjaan yang bersifat khusus dan sempit. Pihak rumah sakit juga disarankan memberikan penghargaan kepada karyawan yang sudah mengerjakan tugasnya dengan baik, kesesuaian gaji dan beban kerja yang diberikan juga perlu diperhatikan dengan baik agar kepuasan kerja karyawan tetap tinggi. Hal-hal tersebut dapat mengendalikan tingkat stres kerja dan juga menjaga kepuasan karyawan agar tetap tinggi, yang secara tidak langsung dapat mencegah karyawan memiliki keinginan meninggalkan organisasi dan mencari pekerjaan di tempat lain.

Penelitian ini hanya sebatas meneliti mengenai stres kerja, kepuasan kerja dan turnover intention. Penelitian selanjutnya diharapkan untuk bisa menambah variabel-variabel lain karena penelitian ini hanya meneliti turnover intention yang dipengaruhi oleh stres kerja dan kepuasan kerja, namun tidak menutup kemungkinan munculnya faktor lain diluar penelitian ini.

\section{REFERENSI}


Abdillah, F. (2012). Hubungan Kohesivitas Kelompok Dengan Intensi Turnover Pada Karyawan. Journal of Social and Industrial Psychology, 1(2), 52-58.

Ahmad, B., Shahid, M., Zill-E-Huma, \& Haider, S. (2012). Turnover Intention : An HRM Issue in Textile Sector. Interdisciplinary Journal of Contemporary Research In Business, 3(12), 125-130.

Arshadi, N., \& Damiri, H. (2013). The Relationship of Job Stress with Turnover Intention and Job Performance: Moderating Role of OBSE. Procedia Social and Behavioral Sciences, 84, 706-710.

Basri, M. H. (2017). Pengaruh Stres Kerja Terhadap Turnover Intentions Melalui Kepuasan Kerja Kada CV. Aneka Produksi. Jurnal Ilmu Manajemen, 5(2), $1-7$.

Chandio, J. A., Jhatial, A. A.,\& Mallah, R. (2013). Modeling the Relationship of Unclear Career Development with Job Dissatisfaction, Job Stress and Employees Turnover Intention: Structural Equation Modeling Approach. Journal of Arts Humamanities, 41(41), 55-57.

Chen, Y.-C., Kuo, C., \& Wang, W. C. (2010). Structural Investigation of the Relationship between Working Satisfaction and Employee Turnover. The Journal of Human Resource and Adult Learning, 6(1), 41-50.

Dizgah, M. R., Chegini, M. G., \& Bisokhan, R. (2012). Relationship between Job Satisfaction and Employee Job Performance in Guilan Public Sector. Journal of Basic and Applied Scientific Research, 2(2), 1735-1741.

Faqihudin, M., \& Gunistiyo. (2010). Pengaruh Stres Kerja Terhadap Kepuasan Kerja Dan Intensi Meninggalkan Organisasi Pada Bank-Bank Milik Negara Di Kota Tegal. Jurnal Sekolah Bisnis Dan Manajemen Institut Teknologi Bandung, 5(7), 1-9.

Gillies, Dee Ann. (1989). Manajemen Keperawatan: Suatu Pendekatan Sistem Edisi. 2. (Alih Bahasa : Dika Sukmana dkk). Illioni: WB Saunders Company.

Indrayani, I. G. A. P. W. (2012). Peran Mediasi Kepuasan Kerja Dan Komitmen Organisasional Pada Hubungan Stress Kerja Dengan Intensi Keluar Karyawan. Jural Bisnis Hospitaliti, 1(1), 1-7.

Iqbal, M., \& Waseem, M. A. (2012). Impact of Job Stress on Job Satisfaction among Air Traffic Controllers of Civil Aviation Authority: An Empirical Study from Pakistan. International Journal Of Human Resources Studies, 2(2), 53-70. 
Jehanzeb, K., Rasheed, A., \& Rasheed, M. F. (2013). Organizational Commitment and Turnover Intentions : Impact of Employee' s Training in Private Sector of Saudi Arabia. International Journal of Business and Management, 8(8), 79-90.

Kabungaidze, T., \& Mahlatshana, N. (2013). The Impact of Job Satisfaction and Some Demographic Variables on Employee Turnover Intentions. International Journal of Business Administration, 4(1), 53-65.

Karambut, C. A., \& Noormijati, E. A. T. (2012). Analisis Pengaruh Kecerdasan Emosional, Stres Kerja dan Kepuasan Kerja terhadap Komitmen Organisasional (Studi pada Perawat Unit Rawat Inap RS Panti Waluya Malang). Jurnal Aplikasi Manajemen, 10(3), 655-668.

Mahdi, A. F., Zin, M. Z. M., Nor, M. R. M., Sakat, A. A., \& Naim, A. S. A. (2012). The Relationship Between Job Satisfaction and Turnover Intention. American Journal Of Applied Sciences, 9(9), 1518-1526.

Manurung, M. T., \& Ratnawati, I. (2012). Analisis Pengaruh Stres Kerja dan Kepuasan Kerja Terhadap Turnover Intention Karyawan (Studi Pada STIKES Widya Husada Semarang). Diponegoro Journal Of Management, 1(2), 145-157.

Mosadeghrad, A. M., Ferlie, E., \& Rosenberg, D. (2012). A Study Of Relationship Between Job Stress, Quality Of Working Life And Turnover Intention Among Hospital Employees. Health Service Management Research, 21(3), 211-227.

Nursyamsi, I. (2012). Pengaruh Kepemimpinan, Pemberdayaan, dan Stres Kerja Terhadap Komitmen Organisasional serta dampaknya terhadap Kinerja Dosen. Conference in Business, Accounting, and Management (CBAM), $1(1), 405-423$.

Retnaningrum, A. K., \& Musadieq, M. Al. (2016). Pengaruh Work-Family Cocflict terhadap Kepuasan Kerja dan Kinerja ( Studi pada perawat wanita RSUD Wonosari Yogyakarta ). Jurnal Administrasi Bisnis, 36(1), 72-81.

Salleh, R., Nair, M. S., \& Harun, H. (2012). Job Satisfaction , Organizational Commitment, and Turnover Intention : A Case Study on Employees of a Retail Company in Malaysia. World Academy of Science, Engineering and Technology International Journal of Economics and Management Engineering, 6(12), 3429-3436.

Sartika, D. (2014). Pengaruh Kepuasan Kerja dan Gaya Kepemimpinan Transformasional terhadap Keinginan Keluar Karyawan dengan Komitmen Organisasi sebagai Variabel Mediasi (Studi Kasus di CV. Putra Tama Jaya). Management Analysis Journal, 1(2), 1-11. 
Sheraz, A., Wajid, M., Sajid, M., \& Rizwan, M. (2014). Antecedents of Job Stress and its impact on employee's Job Satisfaction and Turnover Intentions. International Journal Of Learning \& Development, 4(2), 204-226.

Siddiqui, A. A., \& Jamil, R. A. (2015). Antecedents of Employees' Turnover Intentions: Evidence from Private Educational Institutions. American Journal of Economics and Business Administration, 7(4), 160-165.

Sutanto, E. M., \& Gunawan, C. (2013). Kepuasan Kerja, Komitmen Organisasional dan Turnover Intentions. Mitra Ekonomi Dan Manajemen Bisnis, 4(1), 76-88.

Warshawsky, N. E., \& Havens, D. S. (2015). Nurse Manager Job Satisfaction And Intent To Leave. Journal Of Economics, 32(1), 32-39.

Yuda, I. B. D. P., \&Ardana, I. K. (2017). Pengaruh Kepuasan Kerja dan Stres Kerja terhadap Turnover Intention pada Karyawan Hotel Holiday Inn Express. E-Jurnal Manajemen Unud, 6(10), 5319-5347. https://doi.org/10.1037/1064-1297.13.4.311 